Espino, D.P., et al. Analysis of U.S., Kenyan, and Finnish discourse patterns in a cross-cultural digital makerspace learning community through the IBE-UNESCO global competences framework

\title{
Analysis of U.S., Kenyan, and Finnish discourse patterns in a cross-cultural digital makerspace learning community through the IBE-UNESCO global competences framework
}

\author{
Danielle P. Espino \\ Seung B. Lee \\ Lauren Van Tress \\ Toby T. Baker \\ Eric R. Hamilton \\ Pepperdine University \\ *Corresponding Author: danielle.espino@pepperdine.edu \\ Received : 2019-09-01 \\ Accepted : 2019-11-18
}

\begin{abstract}
How to cite this paper: Espino, D. P., Lee, S. B., Van Tress, L., Baker, T., \& Hamilton, E. (2020). Analysis of U.S., Kenyan, and Finnish discourse patterns in a cross-cultural digital makerspace learning community through the IBE-UNESCO global competences framework. Research in Social Sciences and Technology, 5(1),86-100.
\end{abstract}

\begin{abstract}
In 2017, the International Bureau of Education (IBE) at the United Nations Educational, Scientific and Cultural Organization (UNESCO) put forth seven global competences to address accelerating technological progress and increasing levels of complexity and uncertainty affecting many facets of society (Marope, 2017). These competences were used in examining participant discourse in a global, collaborative digital makerspace environment, where students ages 12 to 17 from six countries develop and share STEM-focused media artifacts. The participants communicate synchronously through video conference calls, referred to as online global meet-ups. The meet-ups allow students to present media artifacts they have created, share ideas, exchange information, and provide feedback. In this analysis, epistemic network analysis (ENA), a technique in quantitative ethnography, is used to examine the connections made among the IBE-UNESCO global competences in a meet-up involving participants from Finland, Kenya, and the U.S. ENA network models were created initially for the three sites, then further disaggregated by time segment to analyze how participant discourse patterns may have evolved in each context. Through this approach, the paper explores more broadly the interactive role of media making, cross-cultural engagement, and collaborative learning in the development of global competences in students.
\end{abstract}

Keywords: collaborative learning, epistemic network analysis, global competences, sustainable development goals, transactive discourse 
Espino, D.P., et al. Analysis of U.S., Kenyan, and Finnish discourse patterns in a cross-cultural digital makerspace learning community through the IBE-UNESCO global competences framework

\section{Introduction}

The workforce continues to adapt to the changing needs of technology advances. With revolutionary systems such as complex internet sensors and integrated systems contributing to the rise of Industry 4.0, these developments affect the future of the workforce as well as the learners and education to support it (Marope, 2017). These changes challenge current education systems to thoughtfully examine how to best prepare learners for the unknown future, career readiness, and future curricula in this new landscape (Marope, 2017). In 2015, the United Nations adopted 17 Sustainable Development Goals (SDGs) to address social and economic issues facing global society. SDG\#4 addresses quality education, to provide inclusive and equitable educational opportunities for all. This was further addressed by the Educational 2030 Incheon Declaration and Framework for Action adopted by the United Nations Educational, Scientific and Cultural Organization (UNESCO) in 2016, which expanded on SDG\#4 to provide a new vision for education in 2030. This included Target 4.4, which seeks to "substantially increase the number of youth and adults who have relevant skills, including technical and vocational skills, for employment, decent jobs and entrepreneurship" (UNESCO, p. 20), and Target 4.7, which aims for learners to "acquire knowledge and skills needed to promote sustainable development, including... education for human rights, gender equality, promotion of a culture of peace and non-violence, global citizenship and appreciation of cultural diversity and of culture's contribution to sustainable development" (UNESCO, p. 21). In 2017, the International Bureau of Education (IBE), a program supporting UNESCO, put forth a set of capacity-building competences for education systems that inherently address these targets in their curriculum. These competences, seen in Table 1, reflect the means to equip students to adapt to the shifting needs of Industry 4.0 while developing skill sets in interacting in a globalized context.

This paper examines the reflection of these competences in a current project that addresses both SDG Target 4.4 and 4.7, to build on both relevant skillsets and global citizenship in a learning context. This project involves collaborative STEM (science, technology, engineering, mathematics) focused media making by adolescent participants from various countries in an informal, global makerspace environment. Participants collaborate both asynchronously, using communication tools such as email or Slack (a cloud-based team messaging application), and synchronously through video conference calls known as online global meet-ups. These meetups consist of participants from at least two different project sites who share projects for feedback or discuss projects they are working on together. In these meet-ups, participants frequently discuss STEM-related content and the process of media making as they mutually build on each other's existing knowledge. Transactive discourse (transactivity, looks at the extent to which participants build on the reasoning of others. The presence of transactivity is also examined in this paper as a means to describe the building of observed global competences during the course of the meet-up. 
Espino, D.P., et al. Analysis of U.S., Kenyan, and Finnish discourse patterns in a cross-cultural digital makerspace learning community through the IBE-UNESCO global competences framework

\section{Transactive Discourse}

Transactivity is defined as the extent to which learners operate on the reasoning of their peers. The Transactive Discourse framework is explained as the interaction and reasoning that operates on the reasoning of another (Berkowitz \& Gibbs, 1983). This type of discourse model is crucial in understanding the development of individual reasoning skills through dynamic discussions. Berkowitz (1980) explains that there are two types of transacts: Representational, statements of others without acting on them, and Operational, statements that act on another's reasoning. This study utilizes both Representational and Operational reasoning.

Within an experimental learning setting, the transactive discourse framework can be applied in order to analyze and understand the educational dialogue among students. In their study, Joshi and Rosé (2007) describe transactive discourse in an educational collaborative setting as when students "elaborate, build upon, or argue against the ideas presented" by fellow students, "working towards a common understanding of the task and reaching a shared solution" (p. 53). Within this framework, the participants in this study had the opportunity to interact, engage, contribute, and learn from each other in online meet-ups. Students increased their interpersonal skills while aiming to seek a common solution.

In the same study, Joshi and Rosé (2007) examined the relationship between effective learning in collaborative groups, the process by which all learners work on the learning task together. Students' learning and growth is measured based on how collaborative groups construct arguments and display argumentation. The transactivity of learners' discourse is positively related to individual knowledge acquisition (Teasley, 1997). As these participants effectively build on the contributions of their learning partners, they improve upon their capacity for learning (Joshi \& Rosé, 2007). According to Teasley (1997), the link between transactive reasoning and cognitive change reflects Piaget's notion that when children operate on each other's reasoning, they become aware of contradictions between their reasoning and that of their partner. This cognitive conflict leads to a higher level of understanding that signifies authentic cognitive growth integrating the conflicting viewpoints (Teasley, 1997).

To increase student learning, it is beneficial to enlist a skilled facilitator during computersupported collaborative learning (CSCL). In a study by Berkowitz (1980), students who engaged in formal transactive communication increased the amount of transacts, but only the Representational type; therefore, to increase the transactive communication, new strategies were employed. Consequently, one successful strategy of facilitators was the "plus one" manipulation, or exposure to the reasoning that is one stage higher than one's current stage (Berkowitz \& Gibbs, 1983).

Based on the Transactive Discourse framework of Berkowitz and Gibbs (1983), facilitated discussions between students of various cultures can be analyzed for development and 
Espino, D.P., et al. Analysis of U.S., Kenyan, and Finnish discourse patterns in a cross-cultural digital makerspace learning community through the IBE-UNESCO global competences framework

improvement. Moreover, as students of different cultures engage in partnership, they are encouraged to exchange thoughts, bestow knowledge, and challenge ideas. Essentially, the interaction between each participant strengthens the level of engagement and connection that they form together. As the Operational transaction alone was significantly related to stage change and the Representational transaction was not, both together were more strongly related to change than either alone (Berkowitz \& Gibbs, 1983). The functionality of the transactivity framework depends on the interactive behaviors of the individuals within this setting, and the evidence of how each of them conducts, performs, and ultimately evolves as a result of this setting (Berkowitz \& Gibbs, 1983). The transactivity framework focuses specifically on the relationship between competing positions of different speakers (Joshi \& Rosé, 2007).

CSCL suggests that communication exists with each other via text-based, asynchronous discussion boards, as utilized in this study through the mediums Slack or school-assigned email (Weinberger \& Fischer, 2006). The goal of CSCL is to motivate learning partners to collaborate via the discussion boards, where they have composed a unique written problem in the text that should be analyzed, argued, and refined jointly as a team (Chi, 1997). Weinberger and Fischer (2006) determined that when learners are actively attempting to solve a problem, they are engaging in on-task discourse, demonstrating accurate knowledge of the material related to the task. Further, different strategies may be used to solve the task, thereby increasing efficiency as a result of the individual acquisition of knowledge (Weinberger \& Fischer, 2006).

This current study examines a boundary-crossing perspective of transactive discourse among participants in various countries. Additionally, it offers a new interpretation of the interactions between participants, utilizing online learning communities as a medium for transitivity in learning.

\section{Methodology}

Data for this analysis consisted of discourse data collected during an online global meet-up involving a total of seven students from Finland (1), Kenya (4), and the United States (2). The data was transcribed, resulting in 171 utterances. Each utterance was then coded by two raters for the presence of UNESCO's seven global competences: Lifelong Learning, Self-agency, Interactively Using Diverse Tools and Resources, Interacting with Others, Interacting in and with the World, Trans-disciplinarity, and Multi-literateness. The two raters came to an agreement on the coding through a process of social moderation (Frederiksen et al., 1998; Herrenkohl \& Cornelius, 2013). Table 1 contains the micro-competences as well as sample utterances from the data corresponding to each macro competence. 
Espino, D.P., et al. Analysis of U.S., Kenyan, and Finnish discourse patterns in a cross-cultural digital makerspace learning community through the IBE-UNESCO global competences framework

Table 1. Macro- and micro-competencies with corresponding sample utterances from the meet-up data

\begin{tabular}{|c|c|c|}
\hline Macro-competence & Micro-competences & Sample utterance from transcript data \\
\hline Lifelong Learning & Curiosity, Creativity, Critical thinking & $\begin{array}{l}\text { I like how you used voice over; I don't know how to } \\
\text { do that but I would like to incorporate it, so maybe } \\
\text { one day you could show me how to do that. (U.S. } \\
\text { participant) }\end{array}$ \\
\hline Self-agency & $\begin{array}{l}\text { Initiative/drive/motivation, } \\
\text { Endurance/grit/resilience, Responsibility }\end{array}$ & $\begin{array}{l}\text { The reason I'm proud of that video in particular is it } \\
\text { was like the first script I wrote that we actually got it } \\
\text { all done together and it actually made it to Youtube, } \\
\text { so that was a very proud moment when I saw it was } \\
\text { up on the site and it was being shared and liked. (U.S. } \\
\text { participant) }\end{array}$ \\
\hline $\begin{array}{l}\text { Interactively Using } \\
\text { Diverse Tools and } \\
\text { Resources }\end{array}$ & $\begin{array}{l}\text { Impactful use of resources, Efficient use of } \\
\text { resources, Responsible consumption }\end{array}$ & $\begin{array}{l}\text { My video is about an eggshell and how we should } \\
\text { make use of it because it is useful. It is used to cure } \\
\text { many diseases such as gastric health... It helps the } \\
\text { bone marrow produce healthier blood cells and also } \\
\text { it contains calcium that helps lower high blood } \\
\text { pressure. (Kenyan participant) }\end{array}$ \\
\hline $\begin{array}{l}\text { Interacting with } \\
\text { Others }\end{array}$ & Teamwork, Collaboration, Negotiation & $\begin{array}{l}\text { About my group video kind of project... so how can I } \\
\text { talk with other people in there because I have written } \\
\text { something in there but is there some kind of chat box } \\
\text { or something where I can talk to other people in my } \\
\text { team? (Finnish participant) }\end{array}$ \\
\hline $\begin{array}{l}\text { Interacting in and } \\
\text { with the World }\end{array}$ & $\begin{array}{l}\text { Being local and global, Balancing rights } \\
\text { with privileges, Balancing freedoms with } \\
\text { respect }\end{array}$ & $\begin{array}{l}\text { It was really great meeting you all and I think this is a } \\
\text { really good opportunity for kids like us to connect } \\
\text { with other people who share the same interests as us } \\
\text { around the world, and um yeah, I'm looking forward } \\
\text { to seeing all the videos you make. (U.S. participant) }\end{array}$ \\
\hline Trans-disciplinarity & STEM, Humanities, Social sciences & $\begin{array}{l}\text { I know for STEM, at least when it comes to math, a } \\
\text { lot of people tend to be afraid of math or not want to } \\
\text { deal with math because they find it difficult or like } \\
\text { boring, but this video showed an application in a way } \\
\text { that makes you want to watch. Like, I could see } \\
\text { myself finding that video and like sitting and } \\
\text { watching and thinking aw, that's really cool. (U.S. } \\
\text { participant) }\end{array}$ \\
\hline Multi-literateness & Reading \& writing, Numeracy, Digital & $\begin{array}{l}\text { There's a software, a mathematics software that's } \\
\text { called GeoGebra and I used it... [for] making a bicycle } \\
\text { using mathematics, uh the mathematics concept, so } \\
\text { I used the lines, tangents, circles, and so on to make } \\
\text { a bicycle. (Kenyan participant) }\end{array}$ \\
\hline
\end{tabular}


Espino, D.P., et al. Analysis of U.S., Kenyan, and Finnish discourse patterns in a cross-cultural digital makerspace learning community through the IBE-UNESCO global competences framework

Epistemic network analysis (ENA) was used to examine the connections made between the competences. A technique in quantitative ethnography, ENA uses visualization and statistical techniques to identify meaningful patterns in discourse by analyzing the co-occurrences of constructs (Shaffer, 2017). ENA is grounded in epistemic network theory, which posits that "learning can be characterized by the structure of connections that students make among elements of authentic practice" (Shaffer \& Ruis, 2017, p. 182). ENA utilizes a moving stanza window to identify linkages between constructs within the recent temporal context. For this analysis, a moving stanza window of five lines was used. Furthermore, the data was segmented into six time periods, corresponding to variations in the meet-up's discourse. An overview of each segment is provided in Table 2.

Table 2. Overview of the meet-up data segmentation.

\begin{tabular}{|l|l|l|l|}
\hline Segment & Type & Description & No. of Lines \\
\hline 1 & Introduction & Participants introduce one another. & 18 \\
\hline 2 & Presentation \& feedback & U.S. participant shares a project about a science street fair. & 35 \\
\hline 3 & Presentation \& feedback & Kenyan participant shares a project about using GeoGebra. & 19 \\
\hline 4 & Presentation \& feedback & $\begin{array}{l}\text { Kenyan participant shares a project about the alternative uses } \\
\text { of eggshells. }\end{array}$ & 25 \\
\hline 5 & General Discussion & All participants reflect on their learning from the presentations. & 44 \\
\hline 6 & Closing & $\begin{array}{l}\text { Closing comments and two participants coordinate a future } \\
\text { project. }\end{array}$ & 30 \\
\hline
\end{tabular}

\section{Results}

Figure 1 presents the projected points of each utterance on the two-dimensional ENA space, which accounts for $41.3 \%$ of the variance in the data. The blue dots represent the projected points for the utterances spoken by student participants from the U.S., while the purple and green dots are those of students from Kenya and Finland, respectively. The mean location of each group is indicated by the square of the same color, with the surrounding box signifying the corresponding $95 \%$ confidence intervals.

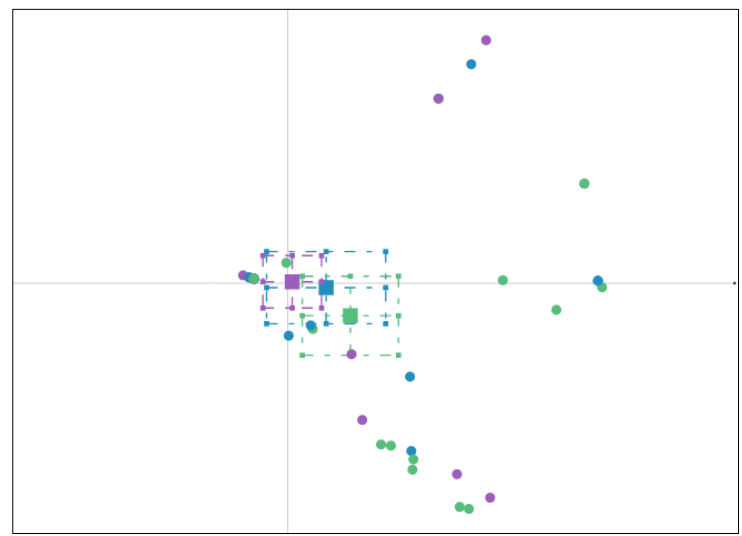

Figure 1. Projected points, mean location, and 95\% confidence intervals for the utterances of U.S. (blue), Kenyan (purple), and Finnish (green) participants. 
Espino, D.P., et al. Analysis of U.S., Kenyan, and Finnish discourse patterns in a cross-cultural digital makerspace learning community through the IBE-UNESCO global competences framework

Figure 2 presents the cumulative mean epistemic network models of the meet-up discourse disaggregated by time segments and the countries of the participants. In the network models, the nodes of the network represent constructs (codes) and the thickness of the edges indicate the relative frequency of co-occurrence-or connection-between them. Thicker edges indicate stronger connections between constructs. Each successive model in the figure represents an aggregation of the connections made in the discourse up to that segment. The final network models are reflective of the average discourse patterns displayed by each group during the entire meet-up.

In segment 1, no significant connections were visible between the seven competencies for all participant groups. Segment 2 included a presentation about a science street fair by a participant from the U.S. The U.S. participants showed a strong connection between Multiliterateness and Interacting in and with the World. These two competences were also moderately linked to Self-agency. Meanwhile, the Finnish participant showed thick connections between Lifelong Learning, Self-agency and Multi-literateness. The Kenyan student participants demonstrated connections between Multi-literateness and Self-agency.

The third time segment comprises a presentation by a Kenyan student on using GeoGebra in a math video, as well as a follow-up discussion. Here, a connection between Multi-literateness and Trans-disciplinary developed for the Kenyan participants. For the U.S. participants, a new connection was seen emerging between Trans-disciplinarity and Lifelong Learning. The network for the Finnish participant remained the same.

In segment 4, a video presentation on the alternative uses for eggshells was delivered by a Kenyan participant and followed by feedback from other students. For the Kenyan participants, a more complex ENA model emerged, with relatively strong connections made between Interactively Using Diverse Tools and Resources and three constructs: Trans-disciplinarity, Selfagency, and Interacting with Others. Linkages between Interacting with Others and Multiliterateness, as well as Self-agency and Trans-disciplinarity, were also seen. The discourse pattern of the U.S. participants also added a strong connection between Interacting with Others and Lifelong Learning. For the Finnish participant, a new connection was seen between Interactively Using Diverse Tools and Resources and Self-agency.

During the general discussion in segment 5, it can be seen that the U.S. and Finnish students were able to expand upon their existing epistemic networks, similar to that of the Kenyan participants in segment 4. For students in the U.S., strong connections emerged between Interacting with Others and both Interactively Using Diverse Tools and Resources and Selfagency, as well as Self-agency and Trans-disciplinarity. For the Finnish participant, a prominent new connection was seen between Interacting with Others and Interacting in and with the World, as well as between Interactively Using Diverse Tools and Resources and Multiliterateness. For the Kenyan students, the network model remained relatively consistent from the previous segment. In the final segment, while some connections became thicker (such as 


\section{ressat}

Research in Social Sciences and Technology

Volume 5 Issue 1, 2020

Espino, D.P., et al. Analysis of U.S., Kenyan, and Finnish discourse patterns in a cross-cultural digital makerspace learning community through the IBE-UNESCO global competences framework

Interacting with Others and Self-agency for the Finnish participant), there were no significant changes to be seen in the networks of the three groups.

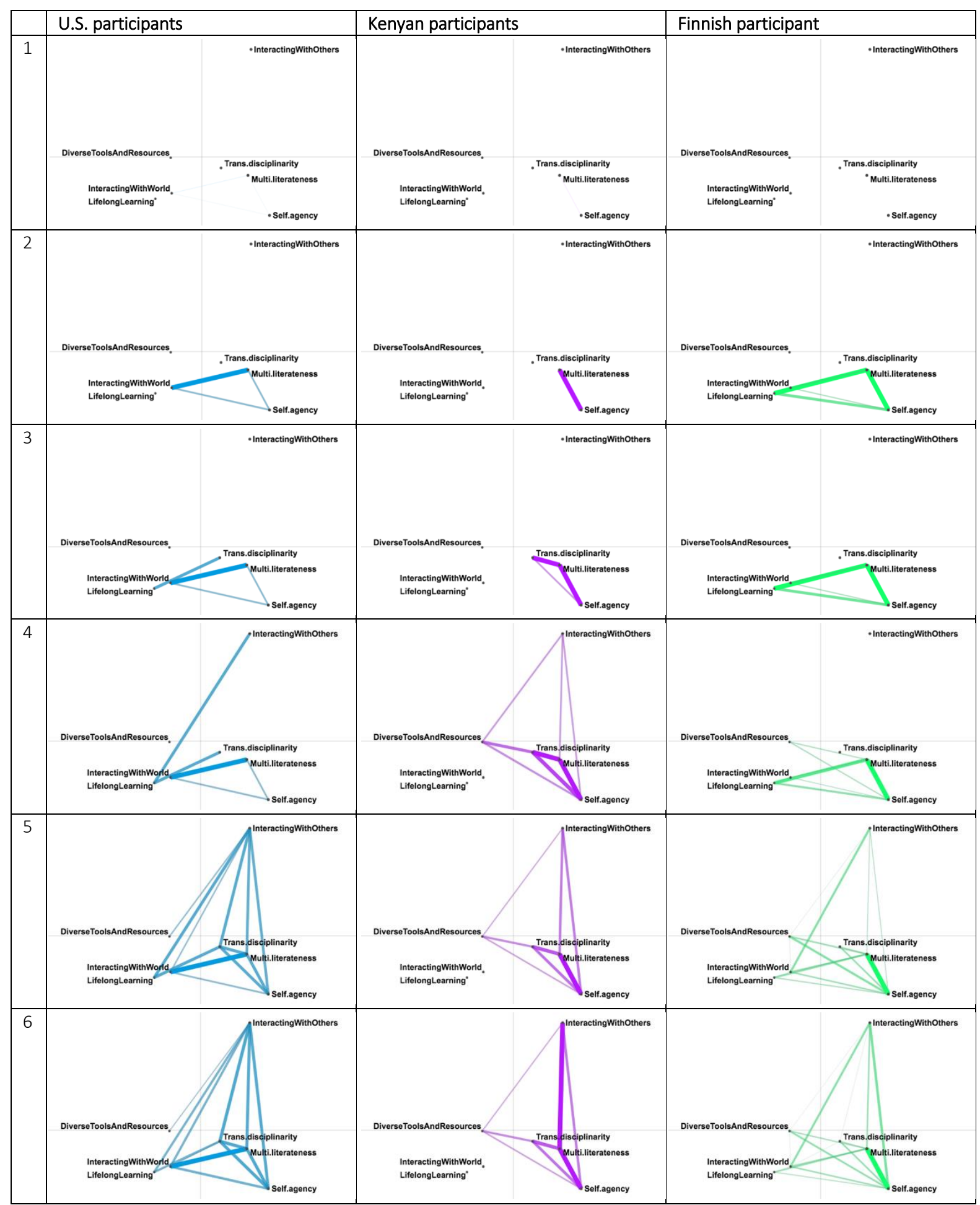

Figure 2. Cumulative mean epistemic network models by time segment and country 
Espino, D.P., et al. Analysis of U.S., Kenyan, and Finnish discourse patterns in a cross-cultural digital makerspace learning community through the IBE-UNESCO global competences framework

\section{Discussion}

Across the online meet-up between the U.S., Kenyan, and Finnish participants, the ENA models show how the presenter topics and competences are subsequently built on and reflected by competences demonstrated by the other two sites. After presenting in segments 3 and 4 , the Kenyan students helped U.S. students build Trans-disciplinarity and the Finnish student build competency around diverse tools and resources. Instead of solely examining the dialogue for evidence of transactive discourse, there is a transactive pattern observed in the ENA models for each site as the time segment progresses. Most of the key activity occurred between segments 2-5, reviewed below.

\section{Segment 2}

The second segment began with a participant from the U.S. sharing a video about a science street fair. Following a question from the facilitator on whether the participant was involved in the editing of the video, a discussion ensued around the topic of media production and the use of video editing software. This topic closely related to digital literacy and was therefore representative of the competence Multi-literateness. In response to the question, the American participant acknowledged a lower level of proficiency in video editing when compared to other roles in filmmaking; however, they expressed interest and efforts in enhancing their skills.

U.S. Participant 1: Was I involved in the editing process? No, not really. My strengths are filming or doing audio or writing or being a talent. Editing is kind of one of my weaker spots so I'm not really involved in editing, but I have been practicing so I can improve.

Participants from Kenya and Finland built on this statement around media making, especially by highlighting their own experiences. The Kenyan participant mentioned their knowledge of a specific video editing software, while the Finnish participant shared both the enjoyable and difficult elements of video production.

Kenyan Participant 1: Actually, I've been making videos. I started making videos in the beginning of the year and I've been using Camtasia to edit.

Finnish Participant: ... I really like to make scripts and talk to people in videos, and I also like to edit. But in the editing process, it's long and hard so I get frustrated. I want the video to be good so it takes time, and sometimes it's very boring, but I really like it, though... I like to come up with different ideas and I also like to plan things, like how do I edit this and how do I explain it and stuff like that, so it's fun, yeah.

\section{Segment 3}

The conversation in the third segment focused on the competence of Trans-disciplinarity, as connections were demonstrated by the U.S. and Kenyan participants, prompted by a video 
Espino, D.P., et al. Analysis of U.S., Kenyan, and Finnish discourse patterns in a cross-cultural digital makerspace learning community through the IBE-UNESCO global competences framework

about an online app that combines algebraic equations with geometric shapes. Using the program, a Kenyan student created a drawing of a bicycle by graphing lines, circles, and other shapes on a Cartesian coordinate system. A student from the U.S. found it interesting that the project was able to link mathematical concepts to everyday objects.

Kenyan Participant 2: ... I thought of an application of mathematics, and looking at a bicycle I saw the segments, which are probably mathematics concepts - the tires are the circles and so on, so I decided to try a bicycle and it worked.

U.S. Participant 1:... for STEM, at least when it comes to math, a lot of people tend to be afraid of math or not want to deal with math because they find it difficult or like boring. But this video showed an application in a way that makes you want to watch, like, I could see myself finding that video and like sitting and watching and thinking, aw that's really cool, I'd like to learn how to do that.

There was limited participation by the Finnish participant, and therefore no change was visible in connections between competences.

\section{Segment 4}

In the fourth segment of this meet-up, a Kenyan participant gave a video presentation on alternative uses for eggshells. The other participants in the meet-up then gave responses and feedback to the presenter. A U.S. participant was impressed by the Kenyan participant's technological skills in making the presentation, noting that they "liked how [they] did voiceover," which was a skill they hadn't yet learned. Thus, the U.S. participant was able to identify a skill that they had not yet learned but wanted to (Lifelong Learning) and provided positive feedback to the Kenyan participant's application of said skill (Interacting with Others). The Finnish participant then reflected on the specific content of the eggshell presentation and was amazed by novel uses of eggshells, saying that the presentation was a "video about a thing which [I] thought was a piece of garbage but it wasn't."

Compared to the earlier segments of this meet-up, the participants formed stronger connections between competences as they watched each other's presentations and ideas. One U.S. participant's response to the eggshell video gave rise to a developing connection between Lifelong Learning and Interacting with Others. The Finnish participant's response connected Self-agency with Interactively Using Diverse Tools and Resources as they acknowledged the usefulness of the presentation video, the novelty of its concepts, and the technology used to create the video.

Finnish Participant: ... I thought the video was amazing. There were good graphics, good text, everything was perfect and I really liked the voiceover as well. There were a lot of beauty tips, which were awesome. I have to try them myself... it's very fun to see that you can make a video about the thing you are throwing... away all the time but you don't think of it as a useful 
Espino, D.P., et al. Analysis of U.S., Kenyan, and Finnish discourse patterns in a cross-cultural digital makerspace learning community through the IBE-UNESCO global competences framework

item or anything like that, so it's very fun to see you make a video about a thing which you thought was piece of garbage but it wasn't. It was very awesome to see that. Thank you for sharing that video, it was awesome.

Since a Kenyan participant was presenting in this time segment, they discussed the video project that they created and received responses by the U.S. and Finnish participants. Thus, the Kenyan participants demonstrated several new strong connections, including Interactively Using Diverse Tools and Resources with Self-agency, Trans-disciplinarity, and Interacting with Others.

\section{Segment 5}

In this segment, all participants shared closing thoughts on the overall meet-up and ideas of video making around STEM subject matters. The U.S. and Finnish participants demonstrated very similar ENA models, which were more developed as a result of segment 4. In these models, the U.S. participants developed a richer link between Self-agency and both Trans-disciplinarity and Interacting with Others, as well as between Interactively Using Diverse Tools and Resources and Interacting with Others. The Finnish participant demonstrated strong connections between Interacting with Others and Interacting with the World, as well as between Interactively Using Diverse Tools and Resources and Multi-literateness. An example of this took place when the Finnish participant complimented the eggshell presentation in segment 4:

Finnish Participant: Well, I actually really love to see other people around the world because I'm very tired of Finnish people... so it's very nice to meet you all and I would really like to make a video of me trying those eggshell things, so is it okay, [Kenyan participant 2], if I'm doing that kind of video, I can share it in the next meeting or something like that... Can I do it?

Another example of the strong connections between Interacting with Others and Self-agency took place later when the U.S. participant described their encouragement to make math videos because of the presentation in segment 3:

U.S. Participant 1: It was nice meeting you all and seeing your videos and hearing your kind of thoughts and comments; now I'm more encouraged I think to make like the math video. I really like that one so now I'm not gonna like shy away from touching on math topics because I'm afraid people won't like them, because I can see now there's a way to make it interesting and so that people would want to watch it. 
Espino, D.P., et al. Analysis of U.S., Kenyan, and Finnish discourse patterns in a cross-cultural digital makerspace learning community through the IBE-UNESCO global competences framework

Table 3. Cumulative summary of strongest connections between competences exhibited in the epistemic network models by time segment and country

\begin{tabular}{|c|c|c|c|}
\hline Segment & U.S. participants & Kenyan participants & Finnish participant \\
\hline 2 & $\begin{array}{l}\text { - Multi-literateness - Interacting } \\
\text { with the World }\end{array}$ & - Multi-literateness - Self-agency & $\begin{array}{l}\text { - } \text { Multi-literateness - Lifelong } \\
\text { Learning } \\
\text { - Self-agency-Multi- } \\
\text { literateness } \\
\text { - Self-agency-Lifelong } \\
\text { Learning } \\
\end{array}$ \\
\hline 3 & $\begin{array}{l}\text { - Multi-literateness - Interacting } \\
\text { with the World } \\
\text { - Lifelong Learning - Trans- } \\
\text { disciplinarity }\end{array}$ & $\begin{array}{l}\text { - Multi-literateness - Self-agency } \\
\text { - Multi-literateness - Trans- } \\
\text { disciplinarity }\end{array}$ & $\begin{array}{l}\text { - } \text { Multi-literateness - Lifelong } \\
\text { Learning } \\
\text { - Self-agency-Multi- } \\
\text { literateness } \\
\text { - Self-agency - Lifelong } \\
\text { Learning } \\
\end{array}$ \\
\hline 4 & $\begin{array}{l}\text { - Multi-literateness - Interacting } \\
\text { with the World } \\
\text { - Lifelong Learning - Trans- } \\
\text { disciplinarity } \\
\text { - Lifelong Learning - Interacting } \\
\text { with Others }\end{array}$ & $\begin{array}{l}\text { - Multi-literateness - Self-agency } \\
\text { - Multi-literateness - Trans- } \\
\text { disciplinarity } \\
\text { - Interactively Using Diverse Tools } \\
\text { and Resources - Interacting with } \\
\text { Others } \\
\text { - Interactively Using Diverse Tools } \\
\text { and Resources - Trans- } \\
\text { disciplinarity } \\
\text { - Interactively Using Diverse Tools } \\
\text { and Resources - Self-agency } \\
\text { - Self-agency - Trans-disciplinarity } \\
\text { - Multi-literateness - Interacting } \\
\text { with Others }\end{array}$ & $\begin{array}{l}\text { - } \text { Multi-literateness - Lifelong } \\
\text { - } \text { Searning } \\
\text { - } \text { literateneness - Multi- } \\
\text { - Self-agency - Lifelong } \\
\text { Learning } \\
\text { - Interactively Using Diverse } \\
\text { Tools and Resources - Self- } \\
\text { agency }\end{array}$ \\
\hline 5 & $\begin{array}{l}\text { - Multi-literateness - Interacting } \\
\text { with the World } \\
\text { - Lifelong Learning - Trans- } \\
\text { disciplinarity } \\
\text { - Lifelong Learning - Interacting } \\
\text { with Others } \\
\text { - Self-agency - Trans- } \\
\text { disciplinarity } \\
\text { - Self-agency - Interacting with } \\
\text { Others } \\
\text { - Interactively Using Diverse } \\
\text { Tools and Resources - } \\
\text { Interacting with Others }\end{array}$ & $\begin{array}{l}\text { - Multi-literateness - Self-agency } \\
\text { - Multi-literateness - Trans- } \\
\text { disciplinarity } \\
\text { - Interactively Using Diverse Tools } \\
\text { and Resources - Interacting with } \\
\text { Others } \\
\text { - Interactively Using Diverse Tools } \\
\text { and Resources - Trans- } \\
\text { disciplinarity } \\
\text { - Interactively Using Diverse Tools } \\
\text { and Resources - Self-agency } \\
\text { - Self-agency - Trans-disciplinarity } \\
\text { - Multi-literateness - Interacting } \\
\text { with Others }\end{array}$ & $\begin{array}{l}\text { - } \text { Multi-literateness - Lifelong } \\
\text { Learning } \\
\text { - Self-agency - Multi- } \\
\text { literateness } \\
\text { - Self-agency - Lifelong } \\
\text { Learning } \\
\text { - Interactively Using Diverse } \\
\text { Tools and Resources - Self- } \\
\text { agency } \\
\text { - Interacting with Others - } \\
\text { Interacting with the World } \\
\text { - Interactively Using Diverse } \\
\text { Tools and Resources - Multi- } \\
\text { literateness }\end{array}$ \\
\hline
\end{tabular}

Note: New connections introduced in the time segment are in italics.

\section{Conclusion}

When looking at dialogue alone, the building of logic and knowledge from participants may not be immediately evident. Utilizing ENA models allows for a visual representation of the competences developed over time in the meet-up, through aggregated models that build with each successive time segment. As the time segments progressed, the ENA models became more complex, demonstrating more connections between competences. A text version of the 
Espino, D.P., et al. Analysis of U.S., Kenyan, and Finnish discourse patterns in a cross-cultural digital makerspace learning community through the IBE-UNESCO global competences framework

progression of these connections seen in ENA is summarized in Table 3. In time segments 2 and 3 , the ENA models across the different participants remained visually similar. However, a key turning point was in segment 4, where a Kenyan student's presentation reflected more connections between competencies and a more complex ENA model. In the remaining time segments, the Finnish and U.S. participants showed similarly complex ENA models, which demonstrated that they built on and adopted similar knowledge and competences to their Kenyan counterparts. In addition, the connections made between constructs such as Interacting with Others, Interacting with the World, and Interactively Using Diverse Tools and Resources address and develop global citizenship among participants.

Across the meet-up, participants helped each other develop key competences, as reflected by the ENA models across time segments 2-6. ENA models helped examine the overarching trend of transactivity that took place as participants exhibited global competences built on by preceding presentations shared during the meet-up. This progressive change in behavior with respect to global competencies supports the importance of considering this media making, boundary-crossing, collaborative environment in learning and building global competences. The project provides insight on how utilizing technology can support global competency development and, in turn, global citizenship.

\section{Acknowledgements}

The authors gratefully acknowledge funding support from the U.S. National Science Foundation (Award \#1612824) for the work this paper reports. Views appearing in this paper do not reflect those of the funding agency. 
Espino, D.P., et al. Analysis of U.S., Kenyan, and Finnish discourse patterns in a cross-cultural digital makerspace learning community through the IBE-UNESCO global competences framework

\section{References}

Berkowitz, M. W. (1980). The role of transactive discussion in moral development: The history of a six-year program of research, Part I [and] Part II. v5 n2 Sum 1980, 5(3), n3.

Berkowitz, M. W., \& Gibbs, J. C. (1983). Measuring the developmental features of moral discussion. Merrill-Palmer Quarterly, 24(4), 399-410.

Chi, M. T. (1997). Quantifying qualitative analyses of verbal data: A practical guide. The Journal of the Learning Sciences, 6(3), 271-315.

Joshi, M., \& Rosé, C. (2007). Using transactivity in conversation for summarization of educational dialogue. Retrieved from: https://www.isca-speech.org/ archive/slate 2007/papers/sle7 053.pdf

Marope, M. (2017). Future competences for future generations. International Bureau of Education: In Focus, 2. Retrieved from: http://ibe-infocus.org/wpcontent/uploads/2018/03/In-Focus-2017.pdf

Shaffer, D. W. (2017). Quantitative ethnography. Madison, WI: Cathcart Press.

Shaffer, D. W., \& Ruis, A. R. (2017). Epistemic network analysis: A worked example of theory-based learning analytics. Handbook of Learning Analytics, 175-187.

Teasley, S. D. (1997) Talking about reasoning: How important is the peer in peer collaboration? In L. B. Resnick, R. Säljö, C. Pontecorvo, \& B. Burge (Eds.), Discourse, tools and reasoning. NATO ASI Series (Series F: Computer and Systems Sciences), vol 160. Berlin: Springer.

United Nations Educational, Scientific and Cultural Organization (UNESCO). (2016). Educational 2030 Incheon Declaration and Framework for Action. Retrieved from https://unesdoc.unesco.org/ark:/48223/pf0000245656

Weinberger, A., \& Fischer, F. (2006). A framework to analyze argumentative knowledge construction in computer-supported collaborative learning. Computers \& Education, 46(1), 71-95. 